\title{
Role of Sequential Functional Echocardiography in Predicting Clinically Apparent Patent Ductus Arteriosus in Preterm Very Low Birth Weight Newborns-An Observational Study
}

Anchala Bhardwaj ( $\nabla$ dranchalasingh@gmail.com )

AllMS Gorakhpur: All India Institute of Medical Sciences Gorakhpur https://orcid.org/0000-0003-46010928

ARVIND SAILI

LHMC New Delhi

Dinesh Kumar Yadav

RML hospital New Delhi

Ajay Kumar

LHMC New Delhi

Research article

Keywords: Preterm newborns, Echocardiography, PDA

Posted Date: December 15th, 2020

DOl: https://doi.org/10.21203/rs.3.rs-125742/v1

License: (c) (i) This work is licensed under a Creative Commons Attribution 4.0 International License.

Read Full License 
Title-Role of Sequential Functional Echocardiography in Predicting Clinically Apparent Patent

Ductus Arteriosus in Preterm Very Low Birth Weight Newborns-An Observational Study

Running Title-Role of Sequential Functional Echocardiography in Predicting Clinically Apparent

Patent Ductus Arteriosus in Preterm Very Low Birth Weight Newborns

\section{Authors-}

1. Dr Anchala Bhardwaj MD DM Neonatology

Assistant Professor

Department of Paediatrics, AIIMS Gorakhpur

Gorakhpur, U.P. India

Email i.d: dranchalasingh@gmail.com

Mobile no: 91-9013600406

2. Dr Arvind Saili MD

Ex Professor and Head

Department of Neonatology

Lady Hardinge Medical College and Associated Hospitals, New Delhi

Email i.d: sailiarvind@gmail.com

3. Dr Dinesh Kumar Yadav MD

Professor Dept Of Paediatrics

Head Division of Paediatric cardiology

PGIMER and Associated Ram Manohar Lohia Hospital, New Delhi

Email i.d: dineshkumar169@yahoo.co.in

4. Dr Ajay Kumar MD

Senior Paediatrician

Department of Neonatology

Lady Hardinge Medical College and Associated Hospitals, New Delhi 
Email i.d: ajayk5@yahoo.com

\section{Corresponding Author}

Dr Anchala Bhardwaj MD DM Neonatology

Assistant Professor

Department of Paediatrics, AIIMS Gorakhpur

Gorakhpur, U.P. India

Email i.d-dranchalasingh@gmail.com

Mobile no: 91-9013600406 


\section{ABSTRACT}

Background-The management of patent ductus arteriosus in preterm neonates continues to be a topic of discussion and controversy. Prolonged ductal patency in preterm neonates has been associated with significant short and long term morbidities and with increased mortality however, policy of routine treatment of all during neonatal period has failed to show significant improvement in long term outcome. Echocardiography has emerged as a promising modality to screen the newborns at risk of adverse effects of ductal shunting. This helps in identifying PDAs that require treatment to ultimately prevent unnecessary therapy or delay of necessary therapy. There are multitude of studies that have evaluated large number of echocardiographic markers for their predictive utility but only few have included all ductal markers together in a single study. The reported sensitivity (26-100\%) and specificity (6-100\%) of echocardiographic markers vary over a wide range. Thus, this study was planned with an aim to assess the predictive utility of all available ductal markers and their added advantage of having all over few ones in clinically apparent PDA in preterm VLBW newborns. Methods-It was an observational prospective study conducted in tertiary care NICU at Lady Hardinge Medical College, Delhi. Fifty preterm very low birth weight (VLBW) newborns underwent four sequential Echo scans within first 72 hrs; first scan within 12 hours then at 24 hrs ,48 hrs and $72 \mathrm{hrs}$ of age and were monitored clinically for the signs of PDA up to two weeks of life or discharge whichever comes later. Results-The Ductal diameter, pulsatile ductal flow pattern, Left pulmonary artery (LPA) velocity, Left atrial to aortic width (La/Ao) ratio, Left atrial volume index (LAVI), Left ventricle to aortic width (Lv/Ao) ratio, E/A ratio and Left ventricular output/superior vena caval (LVO/SVC) flow ratio predicted clinically apparent PDA during first 72 hours of life.

Conclusion-This study provides insights into the predictive utility of other ductal echo markers along with the routinely measured conventional ones during first 72 hours of life in preterm VLBW newborns.

Key words: Preterm newborns, Echocardiography, PDA. 


\section{What is known:}

- Ductal diameter, pulsatile ductal flow pattern, LPA velocity and La/Ao ratio predict development of clinically apparent PDA with wide range of sensitivity and specificity.

\section{What this study adds:}

- LAVI, Lv/Ao ratio, E/A ratio and LVO/SVC flow ratio also predict symptomatic PDA along with the conventional markers.

\section{BACKGROUND}

Prolonged ductal patency in preterm newborns is associated with significant short and long term morbidities with increased mortality $1,2,3,4$. The management of ductus continues to be a topic of interest of many studies. In term infants, the ductus arteriosus constricts soon after birth while in preterm infants, the proportion of patients with a patent ductus and time to closure progressively increases with decreasing gestational age ${ }^{5}$. Approximately $10 \%$ infants of 30 to 37 weeks gestation, $80 \%$ of 25 to 28 weeks gestation and $90 \%$ of those born at 24 weeks gestation would have patent duct by day four of life and $2 \%, 65 \%, 87 \%$ of these in each gestation strata continue to have PDA till day seven of life ${ }^{6}$. Emerging evidences favour the spontaneous closure of ductus in majority of premature newborns by 44-weeks post-menstrual age (PMA) when left untreated with closure rate as high as $73 \%$ in infants $>28$ weeks gestation and $94 \%$ in newborns with birth weight $>1000$ g. 7,8 Echocardiography has emerged as a promising tool to identify patients who may benefit from early therapeutic intervention after scanning their ductal markers profile during first few days of life 5 . Though prolonged patent ductus is associated with poor neurodevelopmental outcome in childhood; policy of universal ductal treatment has failed to demonstrate improvement in long-term outcomes ${ }^{9}$. This has raised the interest of clinicians in studying the predictive utility of echocardiographic markers to identify the high risk infants with increased probabilities of persistent PDA and PDA associated harms ${ }^{10,11,12}$. The goal is to eventually deliver prompt PDA treatment to high risk infants who are most likely to benefit, thereby reducing the side-effects and costs associated with unneces- 
sary and potentially harmful PDA over treatment ${ }^{11,12}$. Till date, multitude of studies have evaluated the predictive utility of large number of echocardiographic markers, however there are handful of studies that have included all ductal markers in a single study. The reported sensitivity (26-100\%) and specificity (6-100\%) of echocardiographic markers vary over a wide range. ${ }^{13} \mathrm{~A}$ comprehensive PDA risk stratification tool based on all echocardiographic markers is thus needed to improve their predictive utility in clinically apparent PDA. Therefore this study included almost all ductal markers with an aim to assess the added advantage of having all over few ones in predicting clinically apparent PDA in preterm VLBW newborns.

\section{METHODS}

AIMS- The primary objective was to assess the predictive utility of all available echocardiographic markers in clinically apparent PDA in preterm VLBW newborns and secondary objective was to study the course of ductus arteriosus in newborns with clinically apparent and not clinically apparent PDA.

Clinically apparent PDA was defined as presence of any one of following signs ${ }^{14}:$ 1) Hyperactive precordium (visible precordial pulsation in $>2$ rib spaces) 2) Systolic murmur (usually ejection systolic murmur of grade $\geq$ III at 1st /2nd Left ICS. 3) Bounding peripheral pulses (easily palpable dorsalis pedis). ${ }^{14,15}$

Following echocardiographic parameters related to ductal size, shunt magnitude and it's hemodynamic consequences on pulmonary and systemic circulations and on cardiac functions were measured. ${ }^{16}$ 1-Ductal diameter 2-Peak systolic velocity across PDA 3-Transductal Velocity Ratio (Ratio of peak systolic velocity at pulmonary end and peak systolic velocity at aortic end) 4-Direction of ductal shunting 5-Shunt flow pattern: There are five Doppler shunt patterns; Pulmonary hypertension pattern, Growing pattern, Pulsatile pattern, Closing pattern and Closed pattern. 6-LPA diastolic velocity 7-La/Ao ratio 8-Left Atrial Volume Index (LAVI) 9-Left ventricular dimensions ( left ventricular end-diastolic dimension (LVEDD), left ventricle end systolic dimension (LVESD) 10- 
Lv/Ao ratio 11-Fractional Shortening (FS) 12-Ejection fraction (EF) 13-E wave/A wave ratio 14Global left ventricular function/Left ventricular Myocardial perfomance index (LV MPI /TEI INDEX) 15-LVO/SVC flow ratio 16-Diastolic flow in post-ductal aorta 17-Diastolic flow in superior mesenteric artery (SMA) and anterior cerebral artery (ACA).

STUDY DESIGN, INCLUSION AND EXCLUSION CRITERIA- This prospective observational study was conducted in neonatal unit of Lady Hardinge Medical College, a tertiary level hospital in New Delhi, India from January 2015 to May 2016.

All preterm VLBW newborns admitted to NICU were assessed for eligibility and newborns with 5 minute Apgar score $\leq 6$, with complex congenital heart disease, with recognisable chromosomal/ congenital malformations, who died before having last confirmatory scan at 2 weeks of life or at discharge whichever was later and whose parents not consented were excluded from the study. The study protocol was approved by the institution's ethics committee.

METHODOLOGY- All enrolled newborns underwent their first echocardiographic scan within 12 hours of birth and subsequent scans later at $24 \mathrm{hrs}, 48 \mathrm{hrs}$ and $72 \mathrm{hrs}$ of age. These scans were performed with a Toshiba 580A ultrasound system using phased array probe $7 \mathrm{MHz}$ for real-time scanning and pulsed/continuous wave/colour Doppler echocardiography and curved probe $6 \mathrm{MHz}$ for doppler scans of anterior cerebral and superior mesenteric arteries (ACA\&SMA). Standard acoustic windows and scanning planes (apical four-chamber view, left parasternal long axis and short axis view, ductal view, suprasternal view and subcostal views) were used to get a complete 2D picture of cardiac anatomy with M-mode measurements of chambers and Doppler evaluation of intra cardiac blood flow. These scans were done by single examiner trained in comprehensive ECHO. All recordings were measured in triplicate and averaged to remove intra observer variation. Images were ob- 
tained with the narrowest sector angle to maximize frame rate (goal frame rate $>100$ frames/s) for optimal image quality. Images were interpreted by a single paediatric cardiologist who was masked to patient and clinical data. The data was collected, coded and stored until final analysis.

These babies were monitored clinically for signs of PDA up to two weeks of age or discharge whichever was later. It has been seen in previous studies that approximately $50 \%$ of VLBW infants and nearly two-thirds of infants with birth weight $>1000 \mathrm{~g}$ undergo spontaneous ductal closure by end of first week; therefore two weeks was chosen as a optimal cut off point for clinical monitoring8. Those who became clinically apparent during this period underwent confirmatory echo scan on that very day while rest who remained free of signs, underwent their last scan at either 14th day of life or at discharge whichever was later to ascertain the closure or persistence of asymptomatic duct. Neonates with clinically apparent PDA received medical (oral ibuprofen or oral/intravenous paracetamol) and surgical interventions for ductal closure as per unit protocol if they were symptomatic along with presence of Hemodynamic significant (Hs) PDA. ${ }^{15}$

Symptomatic and Hs PDA was diagnosed if: La/Ao ratio was $\geq 1.5$ and ductus size measured $>1.5$ $\mathrm{mm}$ and presence of any one of the following symptoms ${ }^{15}$ :

1-Features of congestive heart failure 2-Requiring prolonged respiratory support (invasive or noninvasive) unlikely to be due to other reasons 3-Unexplained oxygen requirement ( $\mathrm{FiO} 2 \geq 30 \%)$ or rising $\mathrm{O} 2$ requirement on respiratory support 4-Recurrent apnea requiring respiratory support (CPAP/Nasal IMV/invasive ventilation) attributed to PDA .

STATISTICAL ANALYSIS -For this study, a convenient sample size of 50 neonates was chosen. Qualitative variables were statistically analysed using chi square test or a Fisher exact test and continuous variables were analysed using Student's t test or Mann-Whitney U test. Univariate analysis and multiple logistic regression analysis were done to assess the association between echocardiographic parameters and clinically apparent PDA. Significance was defined as a $p$ value of less than 
0.05. Cut off points, sensitivity and specificity of significant variables were calculated by plotting ROC curves. The statistical software package SPSS-20 was used for data analysis.

\section{RESULTS}

The study flow is depicted in Fig. 1. The studied cohort of fifty preterm VLBW newborns had a mean gestational age of $30.2 \pm 1.5$ weeks $($ mean \pm SD) and mean birth weight of $1071 \pm 142$ gram (mean \pm SD). Eleven of these 50 newborns had signs of clinically apparent PDA and rest 39 didn't have sign of apparent PDA. The baseline characteristics of newborns are described in Table- 1 . There were no baseline differences between the two groups, except for the number of ELBW babies which was significantly higher (36\%) in clinically apparent PDA group.

The incidence of PDA was $26 \%$ in our study which included clinically not apparent newborns as well because some of them had persistent PDA which was picked up at last echo scan. Two newborns of not clinically apparent PDA group, had small PDA $<1.5 \mathrm{~mm}$ which was detected later in their last discharge scan. Ten babies of clinically apparent PDA group, received medical treatment as per unit protocol for symptomatic and Hs PDA and one of them received 2 courses of medical treatment while none required surgical ligation. The overall spontaneous closure rate was $4 \%$ at 48 hrs of life , $40 \%$ at 72 hrs and $74 \%$ by discharge. Almost one-third of extremely low birth weight (ELBW) babies and nearly two-thirds of babies with birth weight 1000-1500gm exhibited spontaneous closure by discharge. In clinically apparent PDA group, 4 (36.4\%) babies presented with isolated murmur, $2(18 \%)$ with both murmur and hyperkinetic precordium, $1(9 \%)$ with murmur and bounding pulses and $4(36.4 \%)$ with all three signs of clinically apparent PDA. The mean age of presentation was fifth day of life. Several echocardiographic markers were found to predict clinically apparent PDA; each with different cutoff value, sensitivity and specificity at different hours of life during first 3 days of life. These significant qualitative and quantitative parameters measured at different hours of life along with their p value are described in table $2 \& 3$ and the cut off value, 
AUC ( Area under curve), sensitivity and specificity of these parameters are described in table 4. The four echocardiographic parameters in first scan; ductal diameter $\geq 1.7 \mathrm{~mm}$, La : Ao ratio $\geq 1.40$, Lv: Ao ratio $\geq 2.0$ and $\mathbf{L V O} / \mathbf{S V C}$ ratio $\geq 2.5$, six parameters in second scan; shunt flow pattern, ductal size $\geq 1.50 \mathrm{~mm}, \mathrm{La}:$ Ao ratio $\geq 1.4, \mathrm{Lv}$ : Ao ratio $\geq 2$ and $\mathrm{LVO} / \mathrm{SVC}$ ratio $\geq 2.7$, six parameters in third scan; shunt flow pattern, ductal diameter $\geq 1.5 \mathrm{~mm}$, diastolic velocity in LPA $\geq 32.5 \mathrm{~cm} / \mathrm{sec}, \mathbf{L a} / \mathbf{A o}$ ratio $\geq 1.4, \mathbf{L v} / \mathbf{A o} \geq 2.0$ and $\mathbf{L A V I} \geq \mathbf{5} \mathbf{~ m l} / \mathbf{m} 2$ and seven parameters in fourth scan; shunt flow pattern, duct size $\geq 1.5 \mathrm{~mm}$, ductal diameter/weight $\geq 1.4 \mathrm{~mm} / \mathrm{kg}$, La:Ao ratio $\geq 1.4$, Lv:Ao $\geq 2.2$, LAVI $\geq 5.5$ and altered blood flow in systemic vessels predicted clinically apparent PDA. The wider ductal diameter $\geq 1.7 \mathrm{~mm}$ predicted PDA with sensitivity of $91 \%$ and specificity of $80 \%$ within $12 \mathrm{hrs}$ of life while the lesser ductal diameter $\geq 1.5 \mathrm{~mm}$ at 24,48 and $72 \mathrm{hrs}$ predicted same with sensitivity of $90-95 \%$ and specificity of $70 \%-92.3 \%$. The diastolic LPA velocity $\geq 30 \mathrm{~cm} / \mathrm{sec}$ at $24 \mathrm{hrs}$ of life, $\geq 32.5 \mathrm{~cm} / \mathrm{sec}$ at $48 \mathrm{hrs}$ and $72 \mathrm{hrs}$ of life predicted PDA with sensitivity and specificity of $90 \% \& 85 \%, 89 \% \& 85 \%$, and $92 \% \& 87 \%$ respectively. The La/Ao ratio $\geq$ 1.4 predicted clinically apparent PDA with the sensitivity of $46 \%, 55 \%, 73 \%$ and $91 \%$ and specificity of $77 \%, 77 \%, 90 \%$ and $85 \%$ respectively at $12 \mathrm{hrs}, 24 \mathrm{hrs}, 48 \mathrm{hrs}$ and $72 \mathrm{hrs}$ of age. LAVI at a cut-off value of $\geq 5 \mathrm{ml} / \mathrm{m} 2$ at $48 \mathrm{hrs}$ and $\geq 5.5 \mathrm{ml} / \mathrm{m} 2$ at $72 \mathrm{hrs}$ predicted clinically apparent PDA with the sensitivity of $81.8 \%$ and $73 \%$ and specificity of 56.8 and $53 \%$. E/A ratio $\geq 0.95$ and $\geq 1$ at 48hrs and $72 \mathrm{hrs}$ predicted clinically apparent PDA with the sensitivity of $87 \%$ and $88 \%$ and specificity of $82 \%$ and $81 \%$. In this study Lv/Ao $\geq 2$ at $12 \mathrm{hrs}, 24 \mathrm{hrs}, 48 \mathrm{HrS}$ of age and $\geq 2.2$ at $72 \mathrm{hrs}$ of age predicted clinically apparent PDA with the sensitivity of $82 \%, 85 \%, 90 \%$ and $89 \%$ and specificity of $80 \%, 80 \%, 68 \%$ and $82 \%$ respectively. Another parameter $\mathrm{LVO} / \mathrm{SVC}$ ratio $\geq 2.5$ at $12 \mathrm{hrs}$, $\geq 2.7$ at $24 \mathrm{hrs}$ and $\geq 2.9$ at 48 and $72 \mathrm{hrs}$ of age predicted clinically apparent PDA with the sensitivity and specificity of $72 \% \& 77 \%, 87 \% \& 56 \%, 90 \% \& 85 \%, 90 \% \& 87 \%$ respectively. Altered (absent/retrograde) post ductal flow within the first $72 \mathrm{hrs}$ was found to predict clinically apparent PDA with sensitivity of 55\% and specificity of $100 \%$. Altered blood flow in ACA and SMA was 
also found to be significantly associated with later development of clinically apparent PDA. Factors such as birth weight, surfactant treatment, RDS, male gender, sepsis, anemia and history of maternal chorioamnionitis were not significant according to multiple logistic regression analysis for the development of a clinically apparent PDA.

\section{DISCUSSION}

The reported incidence of persistent PDA (PDA beyond day 3 of life) in VLBW infants varies from $18 \%$ to $77 \%$ in inverse relationship with birth weight and gestational age ${ }^{17,18}$. The incidence of PDA was $26 \%$ in our study which was closer to lowest limit of reported incidence. This low incidence can be explained by two possible reasons: first; the studied cohort was relatively mature with average birth weight of 1071 gm with only $12 \%$ proportion of ELBW babies and second; our policy of giving selective therapeutic interventions to newborns with symptomatic Hs PDA only in accord to recent evidences supporting spontaneous ductal closure in majority of premature patients ${ }^{19}$. In this study $74 \%$ of newborns had spontaneous ductal closure by discharge. The closure rate was higher in more mature newborns as nearly two-third of babies with birth weight $>1000 \mathrm{~g}$ compared to only one-third of ELBW babies underwent spontaneous ductal closure. Our results were similar to other studies that had found that more than half of the VLBW infants undergo spontaneous ductal closure by 44 weeks post menstrual age if left untreated 7,8 . Nemerofsky et al. reported closure rate of $71 \%$ in VLBW newborns with two times higher rate among infants whose birth weight $>1000 \mathrm{~g}$ than among those infants with birth weight $<1000 \mathrm{~g}(67 \% \text { versus } 31 \% \mathrm{p}<0.01)^{8}$. In an another study by Koch et al., 35\% of extremely low birth weight infants were shown to have spontaneous ductal closure within the first 10 days of life ${ }^{7}$. He found the direct relationship between gestational age and spontaneous closure and estimated that for each additional week above 23 weeks, the odds of spontaneous closure increased by a ratio of $1.5^{7}$. These findings thus suggest that exposure to the risks of therapeutic interventions for ductal closure might not be warranted in all VLBW newborns. 
The most common presenting sign of clinically apparent PDA was heart murmur which had been seen in majority of previous studies too ${ }^{20}$. Beyond $12 \mathrm{hrs}$ of life, ductal diameter $\geq 1.5 \mathrm{~mm}$ predicted clinically apparent PDA with sensitivity of 90-95\% and specificity of 70\%-92.3\% and within 12 hrs of life, wider ductal diameter $\geq 1.7 \mathrm{~mm}$ was required to had same predictive value. The utility of ductal diameter in predicting ductal patency had already been validated in many of previous studies $^{21,22,23,24}$. In this study, pulsatile shunt flow pattern across the duct was found to predict the ductal patency with sensitivity of $91 \%$ and specificity of $100 \%$. Very few studies have assessed the predictive role of shunt flow pattern in PDA and that too with mixed results $22,25,26$. Su et al. and Harling et al. found that the pulsatile ductal flow pattern could predict symptomatic PDA while Visconti et al. did not find significant difference in transductal flow pattern between two groups of newborns with and without PDA $22,25,26$. Normally pulmonary artery has only systolic laminar flow with velocity $<1.5 \mathrm{~m} / \mathrm{s}$ while in presence of PDA, it shows diastolic flow along with turbulence in systolic flow pattern ${ }^{16}$. Thankavel et al. found the role of LPA diastolic velocity $<30 \mathrm{~cm} / \mathrm{sec}$ measured at $72 \mathrm{hrs}$ of life in predicting closure of ductus in preterm newborn $<30$ weeks $^{27}$. We too had similar results but with different cutoff at different hours of life. The diastolic LPA velocity $\geq 30 \mathrm{~cm} / \mathrm{sec}$ at $24 \mathrm{hrs}$ of life, $\geq 32.5 \mathrm{~cm} / \mathrm{sec}$ at $48 \mathrm{hrs}$ and $72 \mathrm{hrs}$ of life predicted PDA with sensitivity and specificity of $90 \%$ $\& 85 \%, 89 \% \& 85 \%$, and $92 \% \& 87 \%$ respectively. The predictive role of La:Ao ratio for PDA is well established but with wide variation in sensitivity and specificity across the available literature $22,23,28$. Moreover, it is considered to be an inferior marker of PDA severity than LAVI29,30. There are three explanations to this; 1-La: Ao ratio measures atrial enlargement along the AP axis only and if LA dilates predominantly in the superior-inferior and medial-lateral directions, it can underestimate atrial enlargement 2-Decompression of left atrium via patent foramen ovale may also underestimate the magnitude of ductal shunt even in the presence of large duct. 3-In many preterm newborns, the size of the aorta is also enlarged and thus even if the left atrium increases, the La/Ao ratio may remain unchanged. Though left atrial volume index (LAVI) remains higher in newborns with 
Hs PDA; predictive utility of this marker for PDA is not studied much till date ${ }^{30}$. In our study, LAVI at a cut-off value of $\geq 5 \mathrm{ml} / \mathrm{m} 2$ at $48 \mathrm{hrs}$ and $\geq 5.5 \mathrm{ml} / \mathrm{m} 2$ at $72 \mathrm{hrs}$ predicted clinically apparent PDA with sensitivity of $81.8 \%$ and $73 \%$ and specificity of 56.8 and $53 \%$ respectively. We did not find significant differences in LVED dimension, LVES dimension, LVEF and FS between newborns who later developed clinically apparent PDA and those who remained asymptomatic during the course of study. The same results were obtained in other studies too 21,26 . E/A ratio, Lv/Ao and LVO/ SVC are the parameters which had been extensively studied in context to diagnosing Hs PDA but their predictive role for determining persistence of ductus were not studied much till date $21,27,31,32$. In our study, all these three parameters were found to predict PDA; each with different cut-off values at different hours of life. Altered blood flow in aorta, anterior cerebral and in superior mesenteric vessels seen within $72 \mathrm{hrs}$ of life was also found to predict the persistence of ductus arteriosus much before its clinical detection. Kluckow et al. showed that the altered post ductal aortic diastolic flow (unclear direction to flow or retrograde flow) at 19 hours of life could predict symptomatic PDA with sensitivity of $68 \%$ and specificity of $85 \%$ in preterm babies ${ }^{23}$. Our observations confirm it and further add to the limited existing literature on predictive PDA markers.

This is one of the few studies that have been done to date on all predictive markers of PDA being assessed together in a single study. Though this study does not analyse the natural course of ductus in preterm newborns but it reflects the current conservative approach for PDA management. In view of current clinical standards, it would be impossible to devise a study without PDA treatment.

There are some limitations to our study. This was a prospective cohort study with very small sample size of 50 newborns only. The studied cohort was relatively mature in terms of weight and gestational age with less no of ELBW babies who are actually the most susceptible population to suffer PDA related morbidities. The clinical and biochemical markers related to ductal patency were not studied in conjunction with echocardiographic markers for their predictive role. 


\section{CONCLUSION}

This study provides insights into the predictive utility of other less studied markers eg Lv/Ao ratio, LAVI, E/A ratio and LVO/SVC flow ratio along with conventional ones e.g. ductal diameter, pulsatile ductal flow pattern, LPA velocity and La/Ao ratio in clinically apparent PDA during first 72 hours of life. An another research with larger sample size is warranted in future for formulating a comprehensive predictive tool using all these parameters along with clinical and biochemical factors in extremely preterm neonates to guide the early and selective treatment approach.

Abbreviations: LPA-Left pulmonary artery, La: Ao-Left atrial to aortic width, LAVI-Left atrial volume index, Lv:Ao-Left ventricle to aortic width, LVO/SVC Left ventricular output/superior vena cava, NICU-Neonatal intensive care unit, PDA-Patent ductus arteriosus, VLBW-Very low birth weight.

\section{Declarations:}

Ethics approval and consent to participate- The study protocol was approved by the institution's ethics committee. Informed written consent was taken from parents/gaurdian before enrolling the case in to study.

\section{Consent for publication- Not applicable}

Availability of data and materials- The datasets used and/or analysed during the current study are available from the corresponding author on request.

Competing interests- The authors declare that they have no conflict of interest.

Funding-There is no funding source.

Authors' contributions-AS-contributed to conception or design, AB-drafted the manuscript DYcontributed to acquisition, analysis, or interpretation, AK, AS-critically revised the manuscript. 


\section{REFERENCES}

1.Shimada S, Kasai T, Konishi M, Fujiwara T. Effects of patent ductus arteriosus on left ventricular output and organ blood flows in preterm infants with respiratory distress syndrome treated with surfactant. J Pediatr.1994;125:270-277.

2.Jim WT, Chiu NC, Chen MR, Hung HY, Kao HA, Hsu CH et al. Cerebral hemodynamic change and intraventricular haemorrhage in very low birth weight infants with patent ductus arteriosus. U1trasound Med Biol. 2005; 31: 197-202.

3.Kabra NS, Schmidt B, Roberts RS, Doyle LW, Papile L, Fanaroff A. Neurosensory impairment after surgical closure of patent ductus arteriosus in extremely low birth weight infants: results from the Trial of Indomethacin Prophylaxis in Preterms. J Pediatr. 2007; 150: 229-234.

4.Smith A, McNamara PJ, EL-Khuffash AF.Non-pharmacological management of a hemodynamically significant patent ductus arteriosus.Seminars in Fetal and Neonatal Medicine.2018; 23(4): 245-249.

5. Benitz WE, Bhombal S.Patent Ductus Arteriosus. In:Martin RJ, Fanaroff AA, Walsh MC, eds. Neonatal Perinatal Medicine- Diseases of the Fetus and infant. 11 th Edition. Philadelphia: Elsevier ; 2020. p.1334-41.

6.Benitz WE. Committee on Fetus and Newborn. Patent Ductus Arteriosus in Preterm Infants. Pediatrics. 2016;137(1):e20153730

7.Koch J, Hensley G, Roy L, Brown S, Ramaciotti C, Rosenfeld CR. Prevalence of spontaneous closure of the ductus arteriosus in neonates at a birth weight of 1000 grams or less. Pediatrics. 2006;117(4):1113-1121

8.Nemerofsky SL, Parravicini E, Bateman D, Kleinman C, Polin RA, Lorenz JM. The ductus arteriosus rarely requires treatment in infants $>1000$ grams. Am J Perinatol. 2008;25(10):661-666

9.Mitra S, Florez ID, Tamayo ME, Mbuagbaw L, Vanniyasingam T, Veroniki AA, Zea AM, Zhang Y, Sadeghirad B, Thabane L. Association of Placebo, Indomethacin, Ibuprofen, and Acetaminophen 
With Closure of Hemodynamically Significant Patent Ductus Arteriosus in Preterm Infants: A Systematic Review and Meta-analysis. JAMA. 2018 Mar 27;319(12):1221- 1238

10.Fowlie PW, Davis PG. Prophylactic indomethacin for preterm infants: a systematic review and meta-analysis. Arch Dis Child Fetal Neonatal Ed. 2003; 88: 464-466.

11.Jones LJ, Craven PD, Attia J, Thakkinstian A. Wright I.Network meta-analysis of indomethacin versus ibuprofen versus placebo for PDA in preterm infants. Arch Dis Child Fetal Neonatal Ed. 2011; 96: 45-52.

12.BenitzWE. Treatment of persistent patent ductus arteriosus in preterm infants: time to accept the null hypothesis? J Perinat.2010;30:241-252

13.Jain A,Shah P. Diagnosis, Evaluation, and Management of Patent Ductus Arteriosus in Preterm Neonates.JAMA Pediatr.2015; 169(9):863-72

14.Evans Nick.Management of Patent Ductus Arteriosus in Preterm Infants.Sydney Local Health District Guideline No: RPAH-GL2016-002

15. Patent Ductus Arteriosus in Preterm Neonates. AIIMS protocol.2014

16.Skinner Jonathan, Alverson Dale, Hunter S.Echocardiography for the Neonatologist.Philadelphia: Churchill Livingstone; 2000.

17.Furzan JA, Reisch J, Tyson JE, Laird P, Rosenfeld CR. Incidence and risk factors for symptomatic patent ductus arteriosus among inborn very-low-birth-weight infants. Early Hum Dev. $1985 ; 12: 39-48$.

18.Mouzinho AI, Rosenfeld CR, Risser R. Symptomatic patent ductus arteriosus in very- low-birthweight infants: 1987-1989.Early Hum Dev. 1991; 27: 65-77.

19.Vanhaesebrouck S, Zonnenberg I, Vondervoort P, Bruneel E, Van Hoestenberghe MR, Theyskens

C. Conservative treatment for patent ductus arteriosus in the preterm. Arch Dis Child Fetal Neonatal Ed.2007; 92: 244-247.

20.Pourarian S, Sharma D, Cheriki S, Bijanzadeh F, FarahbakhshN.To evaluate the prevalence of 
symptomatic and non-symptomatic ductus arteriosus and accuracy of physical signs in diagnosing PDA in preterm infants using blinded comparison of clinical and echocardiographic findings during the first week of life: A prospective observational study from Iran. J Matern Fetal Neonatal Med. $2016 ; 21: 1-5$

21. Kwinta P, Rudziński A, Kruczek P, Kordon Z, Pietrzyk JJ. Can early echocardiographic findings predict Patent Ductus Arteriosus? Neonatology. 2009;95:141-148.

22. Harling S, Hansen-Pupp I, Baigi A, Pesonen E. Echocardiographic prediction of patent ductus arteriosus in need of therapeutic intervention. Acta Paediatr. 2011; 100(2):231-235.

23. Kluckow M, Evans N. Early echocardiographic prediction of symptomatic patent ductus arteriosus in preterm infants undergoing mechanical ventilation. J Pediatr. 1995; 127: 774-779.

24. Smith A, Maguire M, Livingstone V, Dempsey EM. Peak systolic to end diastolic flow velocity ratio is associated with ductal patency in infants below 32 weeks of gestation. Arch Dis Child Fetal Neonatal Ed.2015; 100:132-136.

25.Su BH, Watanabe T, Shimizu M, Yanagisawa M. Echocardiographic assessment of patent ductus arteriosus shunt flow pattern in premature infants. Arch Dis Child Fetal Neonatal Ed. 1997; 77(1): $36-40$.

26.Visconti LF, Morhy SS, Deutsch AD, Tavares GM, Wilberg TJ, Rossi Fde S. Clinical and echocardiographic characteristics associated with the evolution of the ductus arteriosus in the neonate with birth weight lower than 1,500g. Einstein. 2013; 11(3): 317-23.

27.Thankavel PP, Rosenfeld CR, Christie L, Ramaciotti C. Early echocardiographic prediction of ductal closure in neonates $\leq 30$ weeks gestation. J Perinatol. 2013;33(1): 45-51.

28.Iyer P, Evans N. Re-evaluation of the left atrial to aortic root ratio as a marker of patent ductus arteriosus. Arch Dis Child Fetal Neonatal Ed. 1994; 70(2):112-117. 
29. Toyoshima K, Masutani S, Senzaki H, Kawataki M, Itani Y. Left atrial volume is superior to the ratio of the left atrium to aorta diameter for assessment of the severity of Patent Ductus Arteriosus in extremely low birth weight infants.Circ J. 2014; 78: 1701 - 1709.

30. Khositseth A, Nuntnarumit P, Chongkongkiat P. Echocardiographic parameters of Patent Ductus Arteriosus in preterm infants. Indian Pediatr. 2011;48: 773.

31.Johnson GL, Breart GL, Gewitz MH, Brenner JI, Lang P, Dooley KJ et al. Echocardiographic characteristics of premature infants with patient ductus arteriosus. Pediatrics.1983; 72(6):864-871

32.EI Hajjar M, Vaksmann G, Rakza T, Kongolo G, Storme L. Severity of the ductal shunt: a comparison of different markers. Arch Dis Child Fetal Neonatal Ed. 2005; 90(5): 419-422.

Total number of VLBW babies assessed for eligibility-242

\begin{tabular}{|l|l|}
\hline \multicolumn{1}{|l|}{} & $\begin{array}{l}\text { Excluded } \\
\text { Newborns with } 5 \text { minute Apgar score } \leq 6-98 \\
\text { Complex congenital heart disease }-7 \\
\text { Recognisable chromosomal/congenital } \\
\text { malformations- } 16 \\
\text { Could not be enrolled due to logistic } \\
\text { reasons }-63\end{array}$ \\
\hline
\end{tabular}

Newborns who died before having last confirmatory scan at 2 weeks of life or at discharge whichever comes later Died within $72 \mathrm{hrs}-5$

Died after 72 hrs-3

Results analysed for 50 cases 
Fig 1: Study Flow

TABLES

\begin{tabular}{|l|l|l|l|}
\hline Parameters & $\begin{array}{l}\text { Newborns with clini- } \\
\text { cally apparent } \\
\text { PDA(n=11) }\end{array}$ & $\begin{array}{l}\text { Newborns without } \\
\text { clinically apparent } \\
\text { PDA (n=39) }\end{array}$ & $p$ value \\
\hline Birth weight in gm $($ mean \pm SD) & $1002 \pm 140$ & $1140 \pm 144$ & 0.53 \\
\hline ELBW n (\%) & $4(36)$ & $2(5)$ & $0.02 *$ \\
\hline Gestational age in weeks (mean \pm SD) & $29.9 \pm 1.5$ & $30.2 \pm 1.6$ & 0.67 \\
\hline Small for gestational age n (\%) & $1(9)$ & $4(10)$ & 0.32 \\
\hline No of Females n $(\%)$ & $4(36)$ & $19(49)$ & 0.35 \\
\hline No of Vaginal delivery n $(\%)$ & $7(64)$ & $25(64)$ & 0.35 \\
\hline No of ANS uncovered n $(\%)$ & $8(73)$ & $23(59)$ & 0.44 \\
\hline $\begin{array}{l}\text { No of newborns received Surfactant } \\
\text { n } \% \text { ) }\end{array}$ & $8(72)$ & $26(67)$ & 0.50 \\
\hline \begin{tabular}{l} 
No of newborns required mechanical ventilation $\mathrm{n}(\%)$ \\
\hline
\end{tabular} & $3(27)$ & $8(21)$ & 0.46 \\
\hline
\end{tabular}

Table-1 Baseline characteristics of newborns with and without clinically apparent PDA. 


\begin{tabular}{|c|c|c|c|c|}
\hline Echo scan & Name of parameter & $\begin{array}{l}\text { Newborns with clin- } \\
\text { ically apparent PDA } \\
\mathrm{n}=11 \\
(\text { mean } \pm \mathrm{SD})\end{array}$ & $\begin{array}{l}\text { Newborns without clin- } \\
\text { ically apparent PDA } \\
\mathrm{n}=39 \\
(\text { mean } \pm \mathrm{SD})\end{array}$ & $\mathrm{p}$ value \\
\hline \multirow[t]{6}{*}{ With in 12 hours } & Duct size (mm) & $1.87 \pm .17$ & $1.54 \pm .17$ & $.001^{*}$ \\
\hline & Diameter/weight $(\mathrm{mm} / \mathrm{kg})$ & $1.82 \pm .40$ & $1.37 \pm .25$ & $.002 *$ \\
\hline & $\mathrm{La} / \mathrm{Ao}$ & $1.4 \pm .09$ & $1.3 \pm .09$ & $.03 *$ \\
\hline & Lv/Ao & $2.1 \pm .18$ & $1.9 \pm .19$ & $.001^{*}$ \\
\hline & $\mathrm{E} / \mathrm{A}$ & $.81 \pm .05$ & $.78 \pm .05$ & $0.04^{*}$ \\
\hline & $\mathrm{LVO} / \mathrm{SVC}$ & $2.8 \pm .08$ & $2.4 \pm .20$ & $.001 *$ \\
\hline \multirow[t]{7}{*}{ At 24 hrs of life } & Ductal size $(\mathrm{mm})$ & $1.77 \pm 0.33$ & $1.35 \pm 0.17$ & $.001^{*}$ \\
\hline & Diameter/weight $(\mathrm{mm} / \mathrm{kg})$ & $1.45 \pm .52$ & $1.20 \pm .24$ & $.03 *$ \\
\hline & LPA $(\mathrm{cm} / \mathrm{sec})$ & $31.6 \pm 6.7$ & $22.3 \pm 3.8$ & $.001^{*}$ \\
\hline & $\mathrm{La} / \mathrm{Ao}$ & $1.4 \pm .11$ & $1.3 \pm .11$ & $.01 *$ \\
\hline & Lv/Ao & $1.94 \pm .24$ & $1.74 \pm .13$ & $.001^{*}$ \\
\hline & $\mathrm{E} / \mathrm{A}$ & $.91 \pm .07$ & $.80 \pm .06$ & $.001 *$ \\
\hline & $\mathrm{LVO} / \mathrm{SVC}$ & $2.8 \pm .35$ & $2.5 \pm .23$ & $0.001 *$ \\
\hline \multirow[t]{4}{*}{ At 48 hrs of life } & Ductal size (mm) & $1.7 \pm .18$ & $1.2 \pm .38$ & $0.001 *$ \\
\hline & Diameter/weight(mm/kg) & $1.6 \pm .40$ & $1.2 \pm .50$ & $0.016^{*}$ \\
\hline & LPA $(\mathrm{cm} / \mathrm{sec})$ & $46.4 \pm 9.3$ & $18.9 \pm 3.9$ & $0.001 *$ \\
\hline & $\mathrm{La} / \mathrm{Ao}$ & $1.4 \pm .09$ & $1.1 \pm .15$ & $0.001 *$ \\
\hline
\end{tabular}




\begin{tabular}{|l|l|l|l|l|}
\hline & LAVI $(\mathrm{ml} / \mathrm{m} 2)$ & $5.6 \pm 1.7$ & $4.7 \pm .6$ & $0.005^{*}$ \\
\hline & LV/Ao & $2.1 \pm .30$ & $1.7 \pm .10$ & 0.00 * $^{*}$ \\
\hline & E/A & $1.06 \pm .10$ & $0.8 \pm .1$ & $0.001^{*}$ \\
\hline & LVO/SVC & $3.0 \pm .40$ & $2.5 \pm .21$ & $0.001^{*}$ \\
\hline At 72 hrs of life & Ductal size $(\mathrm{mm})$ & $1.6 \pm .40$ & $0.73 \pm .70$ & $0.001^{*}$ \\
\hline & Diameter/weight $(\mathrm{mm} / \mathrm{kg})$ & $1.7 \pm .18$ & $0.65 \pm .6$ & $0.001^{*}$ \\
\hline & LPA $(\mathrm{cm} / \mathrm{sec}$ & $49.8 \pm 4$ & $16 \pm 3.2$ & $0.001^{*}$ \\
\hline & La/Ao & $1.4 \pm .20$ & $1.0 \pm .12$ & $0.001^{*}$ \\
\hline & LAVI $(\mathrm{ml} / \mathrm{m} 2)$ & $6.9 \pm 1.9$ & $4.9 \pm .75$ & $0.01^{*}$ \\
\hline & LV/Ao & $2.8 \pm .5$ & $1.7 \pm .5$ & $0.001^{*}$ \\
\hline & E/A & $.97 \pm .13$ & $.87 \pm .07$ & $0.001^{*}$ \\
\hline & LVO/SVC & $3.4 \pm .5$ & $2.5 \pm .2$ & $0.001^{*}$ \\
\hline
\end{tabular}

Table-2 Quantitative echocardiographic parameters with significant $\mathrm{p}$ value on univariate analysis.

\begin{tabular}{|c|c|c|c|c|}
\hline & Parameter & $\begin{array}{l}\text { Newborns with clinical- } \\
\text { ly apparent PDA n=11 }\end{array}$ & $\begin{array}{l}\text { Newborns with clinical- } \\
\text { ly apparent PDA } n=39\end{array}$ & p value \\
\hline \multicolumn{5}{|l|}{ At 24 hrs of life } \\
\hline & $\begin{array}{l}\text { Shunt flow pattern } n \\
(\%)\end{array}$ & $\begin{array}{l}\text { PH 1(9) } \\
\text { Growing 8(73) } \\
\text { Pulsatile 2(18) }\end{array}$ & $\begin{array}{l}\text { PH } 8(21) \\
\text { Growing 12(31) } \\
\text { Closing 19(48\%) }\end{array}$ & $0.0001 *$ \\
\hline \multicolumn{5}{|l|}{ At 48 hrs of life } \\
\hline & $\begin{array}{l}\text { Shunt flow pattern } n \\
(\%)\end{array}$ & $\begin{array}{l}\text { Growing 2(18) } \\
\text { Pulsatile 9(82) }\end{array}$ & $\begin{array}{l}\text { Growing 2(5\%) } \\
\text { Closing 35(90\%) } \\
\text { Closed 2(5\%) }\end{array}$ & $0.0001 *$ \\
\hline \multicolumn{5}{|l|}{ At 72 hrs of life } \\
\hline & $\begin{array}{l}\text { Shunt flow pattern } n \\
(\%)\end{array}$ & $\begin{array}{l}\text { Pulsatile } 10(90.9) \\
\text { Growing 1(9) }\end{array}$ & $\begin{array}{l}\text { Closing 22(56) } \\
\text { Closed 17(44) }\end{array}$ & $0.0001^{*}$ \\
\hline & $\begin{array}{l}\text { Diastolic blood flow in } \\
\text { post ductal aorta } \mathrm{n}(\%)\end{array}$ & $\begin{array}{l}\text { Absent } 5(45.5) \\
\text { Retrograde } 4(36.3)\end{array}$ & Normal 39(100) & $0.0001 *$ \\
\hline & $\begin{array}{l}\text { Diastolic blood flow in } \\
\text { ACA } n(\%)\end{array}$ & $\begin{array}{l}\text { Absent } 4 \text { (36.3) } \\
\text { Retrograde } 3(27.2)\end{array}$ & Normal 39(100) & $0.0001 *$ \\
\hline & $\begin{array}{l}\text { Diastolic blood flow in } \\
\text { SMA n (\%) }\end{array}$ & $\begin{array}{l}\text { Absent } 4 \text { (36.3) } \\
\text { Retrograde } 3(27.2)\end{array}$ & Normal 39(100) & $0.0001 *$ \\
\hline
\end{tabular}

Table-3 Qualitative echocardiographic parameters with significant $p$ value on univariate analysis. 


\begin{tabular}{|c|c|c|c|c|c|}
\hline & Parameter & Cut off value & AUC & Sensitivity (\%) & Specificity (\%) \\
\hline \multicolumn{6}{|l|}{ Within 12 hrs } \\
\hline & Ductal size (mm) & $\geq 1.7$ & 0.921 & 90.9 & 79.5 \\
\hline & Ductal size/ & $\geq 1.5$ & 0.665 & 81.8 & 51.3 \\
\hline & LA:AO & $\geq 1.4$ & 0.692 & 45.5 & 76.9 \\
\hline & LV:AO & $\geq 2$ & 0.809 & 81.8 & 79.5 \\
\hline & $\mathrm{LVO} / \mathrm{SVC}$ & $\geq 2.5$ & 0.854 & 71.7 & 77.2 \\
\hline \multicolumn{6}{|l|}{ At 24 hrs of life } \\
\hline & Ductal size (mm) & $\geq 1.5$ & 0.923 & 94 & 71.8 \\
\hline & Ductal size/ & $\geq 1.5$ & 0.709 & 90.9 & 56.4 \\
\hline & diastolic velocity & $\geq 30$ & 0.921 & 90.2 & 84.6 \\
\hline & LA:AO & $\geq 1.4$ & 0.739 & 54.5 & 76.9 \\
\hline & LV:AO & $\geq 2$ & 0.790 & 85.5 & 79.5 \\
\hline & LVO/SVC & $\geq 2.7$ & 0.794 & 86.9 & 56.4 \\
\hline \multicolumn{6}{|l|}{ At 48 hrs of life } \\
\hline & Ductal size (mm) & $\geq 1.5$ & 0.900 & 95 & 92.3 \\
\hline & Ductal size/ & $\geq 1.4$ & 0.740 & 72.7 & 61.5 \\
\hline & diastolic velocity & $\geq 32.5$ & 0.964 & 89.3 & 85.4 \\
\hline & LA:AO & $\geq 1.4$ & 0.925 & 72.7 & 89.7 \\
\hline & LV:AO & $\geq 2$ & 0.867 & 90.4 & 67.7 \\
\hline & LAVI & $\geq 5.0$ & 0.683 & 81.8 & 56.8 \\
\hline & $\mathrm{E} / \mathrm{A}$ & $\geq .95$ & 0.864 & 87.1 & 82.5 \\
\hline & $\mathrm{LVO} / \mathrm{SVC}$ & $\geq 2.9$ & 0.854 & 89.9 & 84.9 \\
\hline \multicolumn{6}{|l|}{ At 72 hrs of life } \\
\hline & Ductal size (mm) & $\geq 1.5$ & 0.901 & 95.1 & 89 \\
\hline & Ductal size/ & $\geq 1.4$ & 0.805 & 90.9 & 61.5 \\
\hline & diastolic velocity & $\geq 32.5$ & 0.905 & 92.4 & 87.3 \\
\hline
\end{tabular}




\begin{tabular}{|l|l|l|l|l|}
\hline LA:AO & $\geq 1.4$ & 0.953 & 90.9 & 84.6 \\
\hline LAVI & $\geq 5.5$ & 0.653 & 73.4 & 53.5 \\
\hline LV:AO & $\geq 2.2$ & 0.930 & 89.3 & 82 \\
\hline E/A & $\geq 1$ & 0.856 & 88.1 & 81.4 \\
\hline LVO/SVC & $\geq 2.9$ & 0.900 & 89.6 & 87.2 \\
\hline
\end{tabular}

Table-4 Cut off values of significant echocardiographic parameters and their predictive values. 

Figures

Total number of VLBW babies assessed for eligibility-242

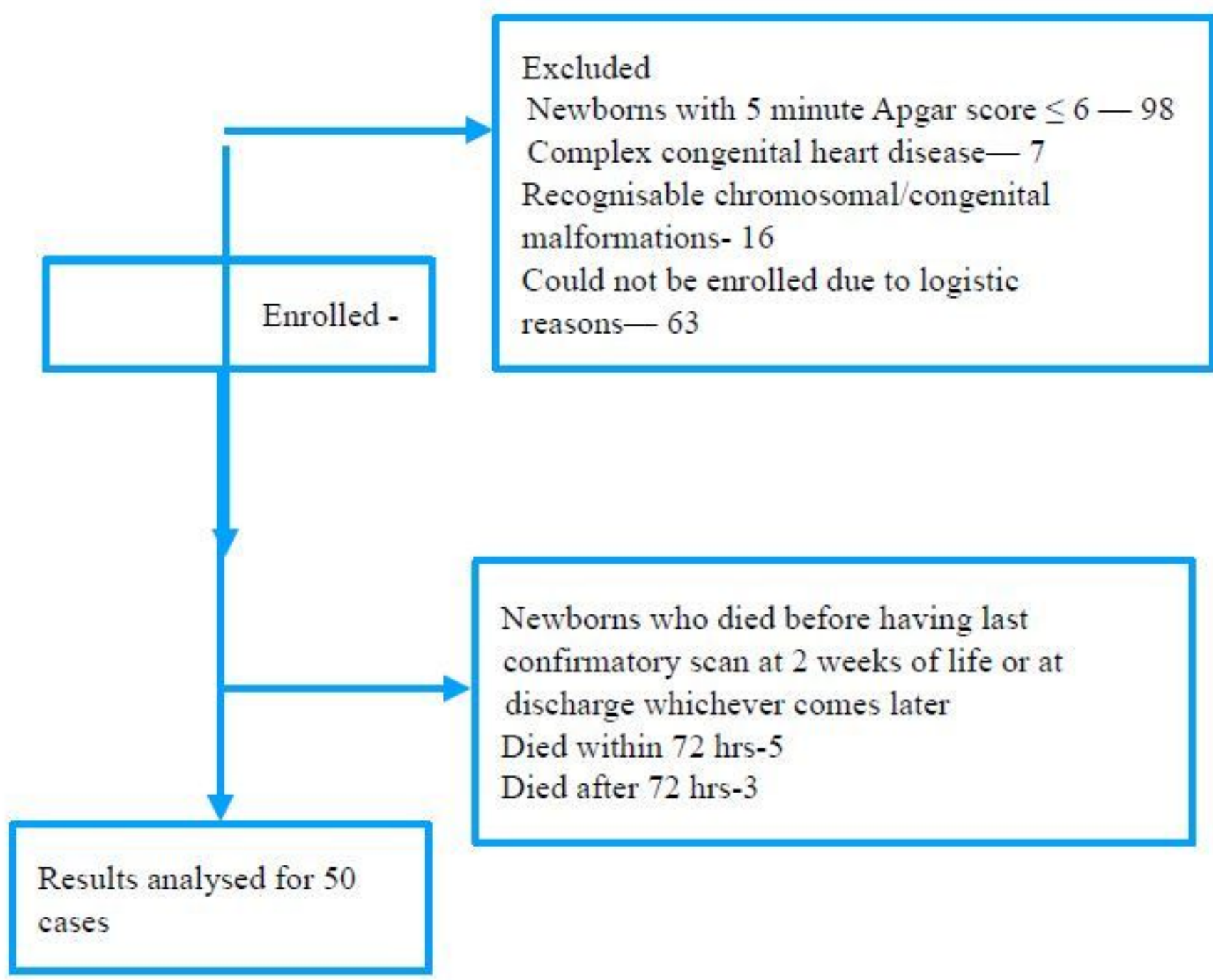

Figure 1

Study Flow 